\title{
ELECTROCARDIOGRAPHIC CHANGES IN INDUCED HYPOTHERMIA IN MAN
}

\author{
BY \\ PETER R. FLEMING AND FRANK H. MUIR \\ From the Cardiac Department, Guy's Hospital \\ Received April 12, 1956
}

Numerous papers have been published in the past few years describing the changes in the electrocardiogram of animals submitted to hypothermia (Prec et al., 1949; Bigelow et al., 1950; Osborn, 1953; and Tysinger et al., 1955) and the pattern is now fairly well established. Information regarding changes in the human cardiogram, however, is scanty and has been derived from various sources.

Electrocardiograms of patients suffering from severe exposure to cold have been reported from time to time by Tomaszewski (1938), who was the first to report the "injury potential" at the QRS-ST junction, Wayburn (1947), Graybiel and Dawe (1950), and Laufman (1951). Kossmann (1940) described the cardiograms of nine patients submitted to hypothermia for advanced malignant disease and was the first to describe the progression of the abnormalities with fall in temperature and to comment on the high incidence of atrial fibrillation The results of the horrible experiments at Dachau, in which prisoners were submitted to hypothermia, have been described in detail by Alexander (1949). Finally, two series of cardiograms of patients operated on under hypothermia have been published by Capretti et al. (1953) and Hicks et al. (1956).

In view of the relatively small number of cases reported so far, less than 50 having been found, we wish to present a series of 29 records of patients submitted to hypothermia for cardiac surgery and to compare them with other published records and with the changes observed in animals.

During the early experimental work on dogs under hypothermia at Guy's Hospital, described by Ross (1954), electrocardiograms were frequently recorded. The changes seen in these records are essentially similar to those described by other workers and will be briefly summarized. It is proposed to refer to experimental work on animals further during the discussion of the human cases, but it should be emphasized at the outset that the changes in the cardiogram during hypothermia in man are not identical with those in animals and conclusions drawn from work on the latter cannot be applied to man uncritically.

In animals, the ventricular rate falls progressively with fall in temperature, and impairment of conduction is manifested early by prolongation of the P-R and QRS intervals; the S-T interval also becomes prolonged (Fig. 1). Nodal rhythm or atrial standstill may occur. At lower temperatures (below $28^{\circ} \mathrm{C}$.) ectopic beats and heart block become more frequent and ventricular fibrillation occurs in a proportion of animals, although some workers have succeeded in cooling dogs until asystole occurred at $10^{\circ}-12^{\circ} \mathrm{C}$. (Tysinger et al., 1955). A deformity of the QRS-ST junction occurs in some dogs (Fig. 2) and seems to be a forerunner of ventricular fibrillation but this point will be discussed more fully later.

The present series comprises 29 of the first 30 patients operated on under hypothermia at Guy's Hospital, no records being available in the remaining one. Electrocardiograms were recorded at frequent intervals throughout the operations. A direct-writing Sanborn cardiograph was used with a screened extension to the patient cable; it was found that interference was eliminated by earthing the patient's right leg terminal to the cable itself, the cardiograph also being suitably 
grounded. No attempt was made to record during the use of diathermy or the electrical defibrillator, and the electric blanket used during the rewarming period was momentarily switched off when a recording was made. Lead II was recorded almost exclusively and all subsequent remarks apply to this lead unless others are specially mentioned.

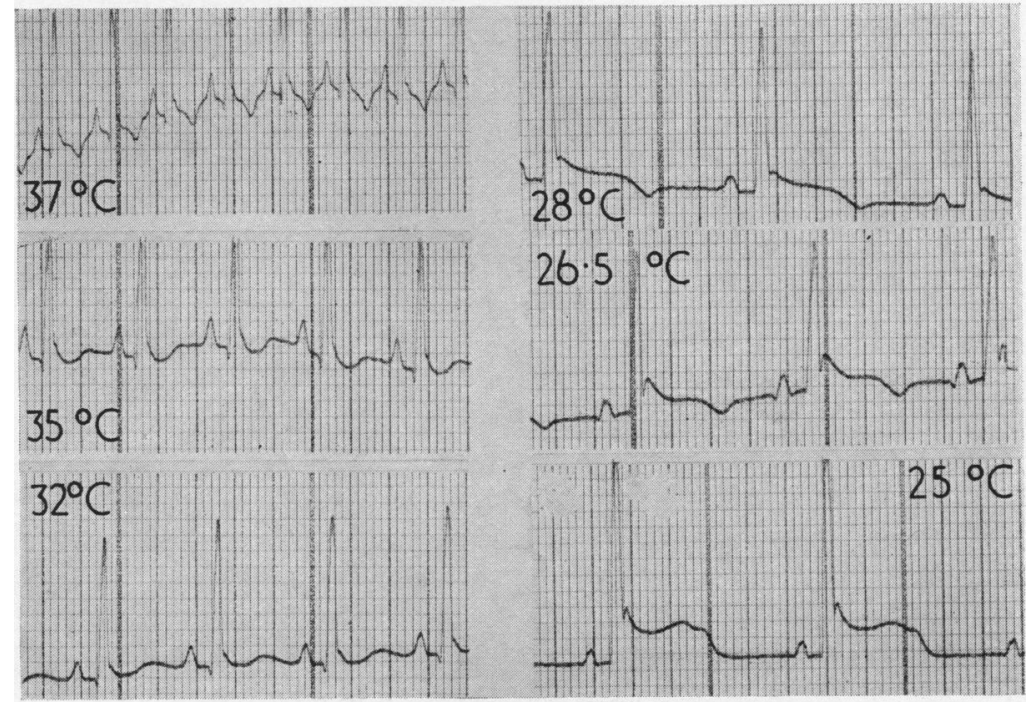

FIG. 1.-Progressive bradycardia with fall in temperature and lengthening of all components of complex. The "injury potential" is first clearly defined at $28^{\circ} \mathrm{C}$. and becomes progressively larger. Lead II of dog during cooling.

The methods of cooling used in this series have been fully described by Brock and Ross (1955) and we need only add that the cardiographic changes were the same whatever technique was used. The temperature was always taken in the pharynx.

There were 11 males and 18 females in this series and their ages ranged from 11 months to 47 years. The diagnoses were as follows: atrial septal defect (10 cases), Fallot's tetralogy (6 cases),

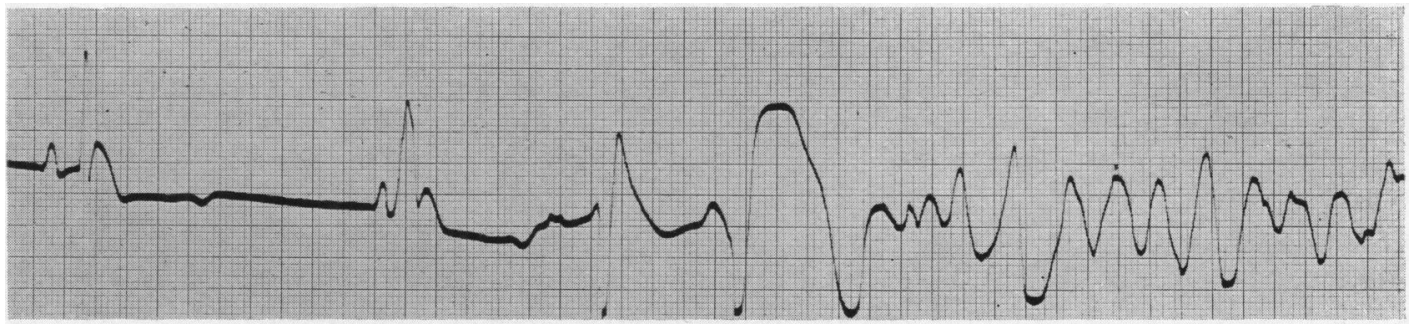

FIG. 2.-The " injury potential" is well developed and the onset of ventricular fibrillation is shown. Lead II of $\operatorname{dog}$ at $20^{\circ} \mathrm{C}$.

patent ductus arteriosus ( 5 cases), pulmonary valve stenosis ( 3 cases), infundibular stenosis ( 2 cases), ventricular septal defect (1 case), aortic stenosis (1 case), and myxoma of the left atrium (1 case).

As we are only concerned here with the changes in the cardiogram produced by hypothermia per se, we have tried to separate off changes due to the anæsthesia or the operation by reference to records of similar operations at normal temperatures (Campbell and Reynolds, 1954) and only 
changes that are seen either very infrequently or not at all in such records have been regarded as due to hypothermia.

\section{Changes Found with Hypothermia}

Changes in Ventricular Rate. All the patients showed a progressive bradycardia with fall of temperature. In animals the relation between fall of ventricular rate and fall of temperature is linear and this was approximately true for most of our patients, but some showed a steeper fall in rate during the early phase of cooling than later; Hicks et al. (1956) noted this frequently. The fall in rate was interrupted by temporary increases when arrhythmias occurred, but with further cooling the ventricular rate continued to fall steadily. The degree of fall in rate varied considerably from patient to patient, the greatest fall being from 185 to 32 and the least from 88 to 72 . The means for the whole series were 130 at normal temperatures, falling to 59 at about $28^{\circ} \mathrm{C}$. just before circulatory occlusion. We did not often see ventricular rates as low as 30 which Scurr (1955) found frequently, except during circulatory occlusion with which we are not primarily concerned in this study. In animals the bradycardia is not abolished by atropine or vagotomy (Burton and Edholm, 1955) and is therefore presumably a direct effect of cold on the pacemaker.

Changes in Rhythm. Apart from occasional ventricular ectopic beats, the arrhythmias observed most frequently in this series during the early stages of cooling were supraventricular in origin. Ectopic atrial rhythms associated with a wandering pacemaker, including nodal rhythm, were frequently seen. Hicks et al. (1956) report similarly, but these arrhythmias are often seen during cardiac surgery at normal temperatures and their association with hypothermia cannot be determined exactly. The general trend of changes is, however, similar to that seen by Crismon (1944) in rats, in which the first effect of cooling was depression of the sinu-atrial node causing bradycardia and the appearance of ectopic atrial rhythms as the excitability of the sinu-atrial node fell below that of other potential pacemakers. Crismon found that complete obliteration of atrial activity occurred before ventricular arrest but Bigelow et al. (1950), working with dogs noticed regular atrial contractions by direct inspection at low temperatures $\left(16^{\circ}-20^{\circ} \mathrm{C}\right.$.), while the ventricles were fibrillating.

In man it seems that the depression of activity of the pacemaker with relative increase in excitability of the atrial myocardium proceeds further and atrial fibrillation was seen frequently in this series. Four patients had atrial fibrillation initially; 17 of the remaining 25 developed this arrhythmia at temperatures varying between $35^{\circ}$ and $28^{\circ} \mathrm{C}$. (mean $31.6^{\circ} \pm 2.4^{\circ} \mathrm{C}$.). In our series of cardiograms of dogs atrial fibrillation hardly ever occurred and this agrees with the findings of other workers with animals. There are possible explanations for this discrepancy; the human hearts were all abnormal and so might be expected to develop arrhythmias more readily, and the cooled blood re-enters the circulation in closer proximity to the sinu-atrial node in clinical hypothermia than in our animal experiments. There is, however, a true species difference as normal men accidently immersed in cold water have been found to develop atrial fibrillation frequently (Wayburn, 1947; Graybiel and Dawe, 1950). The high incidence of this arrhythmia is rendered more striking by the fact that it very rarely occurs during cardiac surgery at normal temperatures. Even if the cases of atrial septal defect-in which atrial fibrillation is a recognized complicationare omitted, the incidence is still very high (13 of 19 cases). We did not find any significant difference between the ages of those who did and did not develop atrial fibrillation.

Preliminary study of our earlier cases (Fleming, 1956) suggested that patients who developed atrial fibrillation had a lower immediate mortality than those who remained in sinus rhythm. This unexpected finding has been confirmed by further study and is illustrated in Table I, the difference between the mortality rates of the two groups being statistically significant. Even if the cases of atrial septal defect, which is associated with a better prognosis than some of the other conditions operated on and also with a tendency to atrial fibrillation, are omitted, the difference between the mortality rates remains significant. We are unable to offer any satisfactory explanation of this finding although it is possible to speculate on the role of acetylcholine in this connection, 
TABLE I

Incidence of Atrial Fibrillation and its Relation to Prognosis

\begin{tabular}{l|c|c|c|c|c|c}
\hline & \multicolumn{4}{|c|}{ All patients (25) } & \multicolumn{2}{|c}{$\begin{array}{c}\text { Omitting those with atrial septal } \\
\text { defect (19) }\end{array}$} \\
\cline { 2 - 7 } \cline { 4 - 7 } & Died & Recovered & $\begin{array}{c}\text { Mortality rate } \\
\text { (percentage) }\end{array}$ & Died & Recovered & $\begin{array}{c}\text { Mortality rate } \\
\text { (percentage) }\end{array}$ \\
\hline $\begin{array}{c}\text { Patients developing atrial } \\
\text { fbrillation } \\
\text { Patients remaining in sinus } \\
\text { rhythm }\end{array}$ & 5 & 12 & 29 & 4 & 9 & 31 \\
\hline
\end{tabular}

and the observations of Riberi et al. (1955) on the beneficial effect in hypothermia of producing blockade of the sinu-atrial node with procaine may be relevant.

Ventricular fibrillation occurred in 21 cases in this series. Although the "injury potential ", discussed below, sometimes gave an indication that it was imminent, it appeared more often with little or no warning (Fig. 3). It began during or immediately after circulatory occlusion in several cases and nearly always in association with manipulation of the heart or great vessels. The part played by hypothermia in causing this arrhythmia is therefore difficult to assess and Delorme (1955) has found that it is extremely rare in dogs under hypothermia in the absence of cardiac

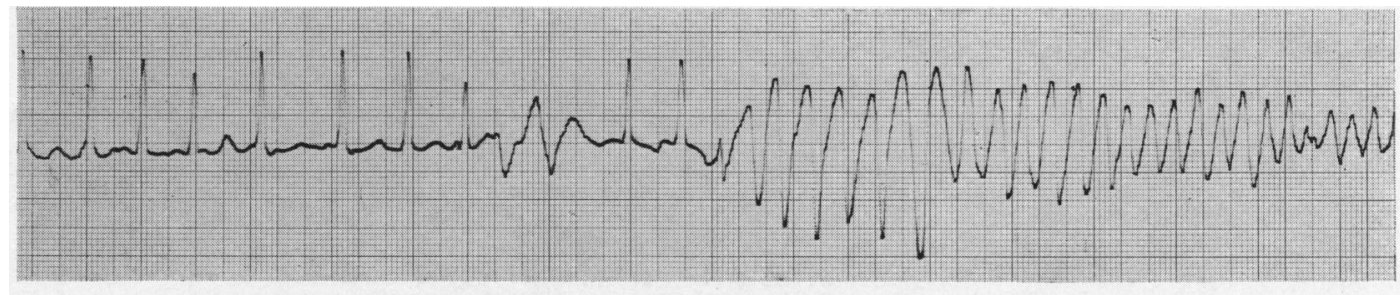

FIG. 3.-Patient with congenital aortic stenosis at $33^{\circ} \mathrm{C}$. Atrial fibrillation began at $34^{\circ} \mathrm{C}$ and the unheralded onset of ventricular fibrillation is shown. At this time, the great veins were being dissected and prepared for occlusion. Lead II.

manipulation. On the other hand, Covino and Charleson (1955) have shown in dogs under hypothermia that the ventricles will respond to artificial stimuli much smaller than would be necessary to excite a response at normal temperatures. They found also that in some dogs the excitability threshold returned to normal levels with further cooling and in these the ultimate outcome was asystole at $15^{\circ}-18^{\circ} \mathrm{C}$; in the others the threshold continued to decline and nearly all these dogs succumbed to ventricular fibrillation between $19^{\circ}$ and $26^{\circ} \mathrm{C}$. This clear separation into two groups of animals, one fore-ordained to ventricular fibrillation and the other virtually immune to it, if confirmed, may explain some of the anomalous results reported in connection with this arrhythmia.

Changes in Electrocardiographic Complexes. Previous workers with animals have emphasized consistent lengthening of all the components of the complex and Hicks et al. (1956) found the same in their patients.

In this series prolongation of the $\mathrm{P}-\mathrm{R}$ interval was seen in 21 of the 25 patients initially in sinus rhythm, but it exceeded the upper limit of normal of $0.2 \mathrm{sec}$. in only 6 of them. The fact that we did not often see great prolongation of the $\mathrm{P}-\mathrm{R}$ interval is probably due to the frequent occurrence of atrial ectopic rhythms, described previously; and it is possible that, if sinus rhythm had persisted throughout in more cases, more would have shown excessively long $\mathrm{P}-\mathrm{R}$ intervals. It can be stated, however, that a long P-R interval above $0.2 \mathrm{sec}$. is not a constant finding during hypothermia as 
in one patient who remained in sinus rhythm throughout cooling it increased from 0.15 to $0.2 \mathrm{sec}$. only, as the temperature fell from $37.5^{\circ}$ to $25.5^{\circ} \mathrm{C}$. It is well known that bradycardia alone will produce an increase in length of the $\mathrm{P}-\mathrm{R}$ interval.

Prolongation of the QRS complex occurred more consistently, being recorded in all but two patients, and the upper normal limit of $0.11 \mathrm{sec}$. was exceeded in 13 of them. The presence of an " injury potential" at the QRS-ST junction, which we have not regarded as part of the QRS complex, renders accurate measurement of the latter difficult and it is worth noting that Campbell and Reynolds (1954) found QRS prolongation occasionally in patients undergoing cardiac surgery at normal temperatures. It seems likely, however, that the consistent finding of prolongation of the QRS in hypothermic animals also applies to man.

Progressive prolongation of the S-T interval (Fig. 4) is the most constant feature of the electrocardiogram during cooling (Muir, 1955). This is to some extent accounted for by the bradycardia

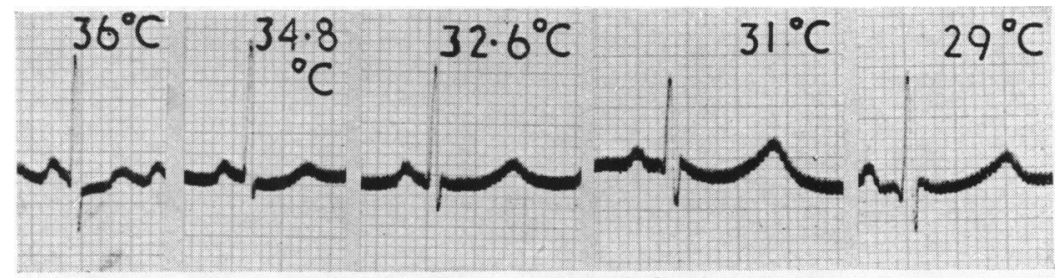

FIG. 4.-Patient with Fallot's tetralogy. The disproportionate prolongation of the S-T interval is shown: P-R increased from 0.12 to 0.16 sec., QRS from 0.06 to $0.08 \mathrm{sec}$., and QTc from 0.46 to $0.57 \mathrm{sec}$. Lead II.

but, after making allowance for this by the method of Taran and Szilagyi (1947), an increase in length of from 30 to 70 per cent of the normal can be demonstrated. This apparent delay in repolarization can be compared with the observations on the effect of cooling the anterior chest wall in man by Rahman et al. (1954) who interpreted their findings as due to a delay in repolarization of the cooled epicardial surface of the heart.

The changes in the ventricular rate and time-relationships of the components of the electrocardiographic complex are illustrated in Fig. 5 and 6. The most striking feature of the cardiogram during hypothermia is the appearance of the "injury potential " at the QRS-ST junction (Fig. 6 and 7). This was seen in six cases in this series and in all but one of these ventricular fibrillation occurred 30-45 minutes after its first appearance. It was usually best seen in lead II. The nature of this abnormal deflection has been in dispute since it was first observed in a man dying of exposure to cold by Tomaszewski (1938), who believed that it represented gross widening of the QRS. It was also recorded by Kossmann (1940) and Laufman (1951) in human patients but without comment on its ætiology. Osborn (1953) demonstrated by recording leads V1 and V6 in dogs that it did not represent a conduction defect and regarded it as an injury potential in the first part of the S-T segment. He noticed that it was a forerunner of ventricular fibrillation and found that it could be made to decline or disappear by decreasing the concentration of carbon dioxide in the inspired air or by increasing the respiratory minute volume. Siems et al. (1955) recorded this wave in 9 out of 20 dogs under hypothermia: they did not comment on its relationship to ventricular fibrillation and believed that it was a prominent Ta wave (atrial $\mathrm{T}$ wave). We do not think this likely as we have frequently recorded it during atrial fibrillation (Fig. 6).

Fresh light on the significance, if not the mechanism, of this abnormality has been provided by the researches of Covino and Hegnauer (1955). The work demonstrating increased excitability of the ventricles in diastole during hypothermia has been amplified by the demonstration of a short period of greatly increased excitability (about 80-fold) occurring in some dogs at the QRS-ST junction. When this large rise in excitability was recorded, the " injury potential " always appeared exactly synchronous with it. They also showed that, both at normal temperatures and during 


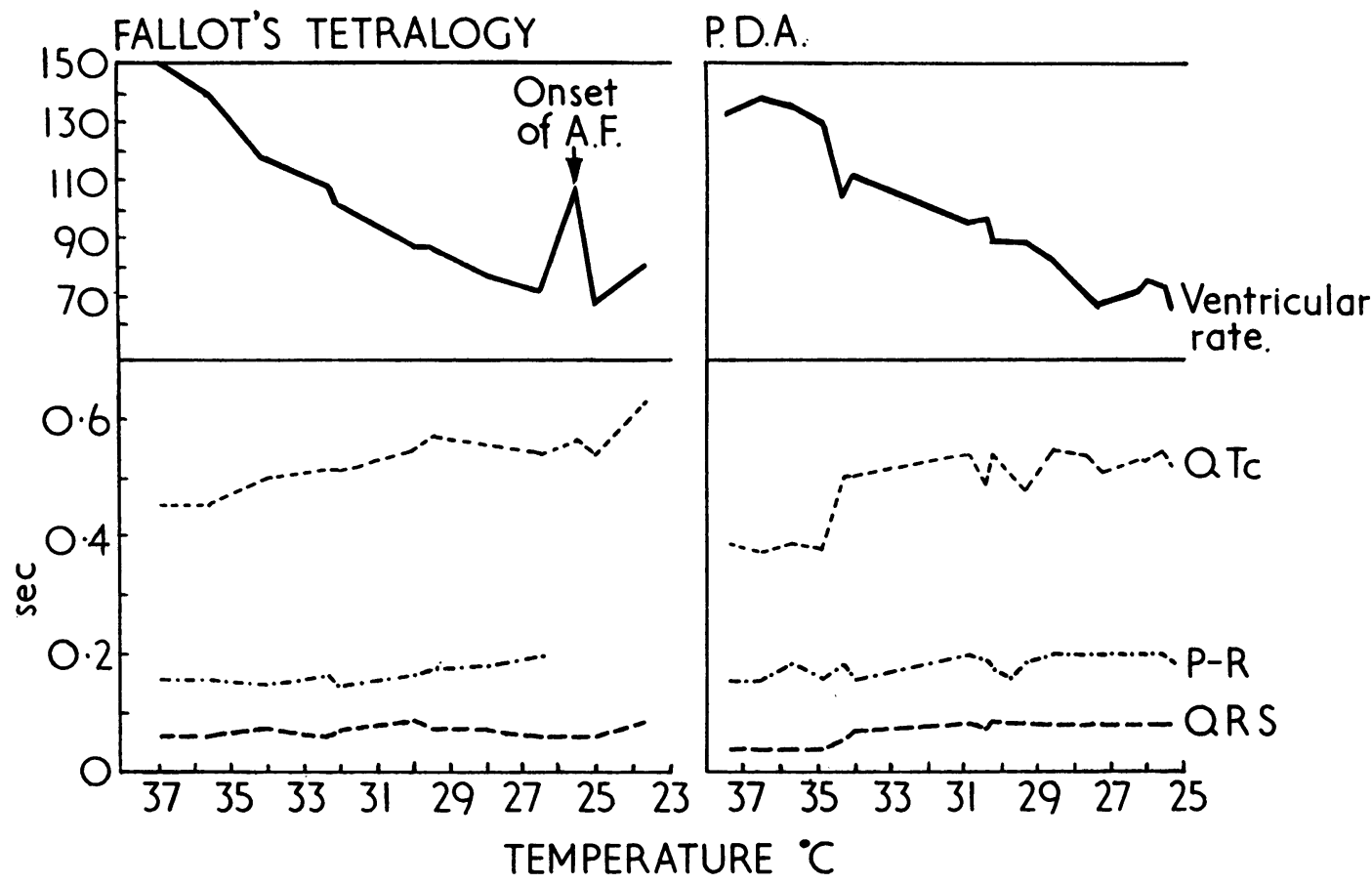

FIG. 5.-Changes in ventricular rate and length of QTc, P-R, and QRS intervals in two patients with fall in temperature.

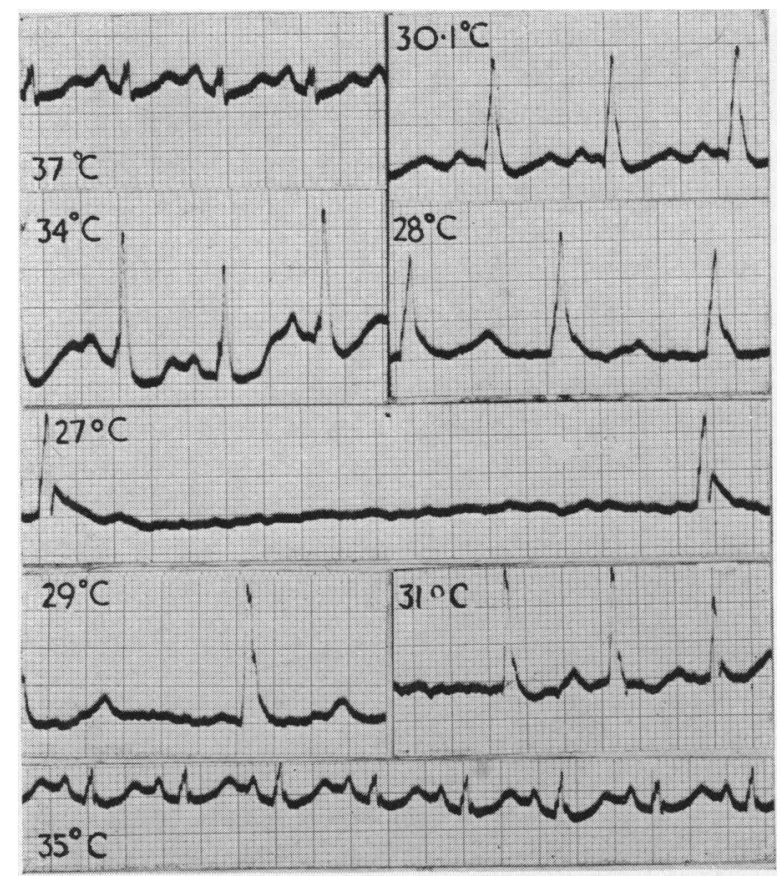

FIG. 6.-Patient with atrial septal defect during cooling and rewarming over a period of 3 hours. All the characteristic features are shown. Atrial fibrillation began at $29^{\circ} \mathrm{C}$. without increase in ventricular rate and sinus rhythm returned at $34^{\circ} \mathrm{C}$. The "injury potential "was first seen at $27 \cdot 5^{\circ} \mathrm{C}$.; this was the only case in which it was not followed by ventricular fibrillation. Lead II. 
hypothermia, this wave was associated with acidosis and that it could be made to disappear by raising the $p \mathrm{H}$ at normal temperatures but not during hypothermia. The empirical observation that the injury potential is a forerunner of ventricular fibrillation is thus supported by the finding that it is an indication of extreme excitability of the ventricular myocardium.

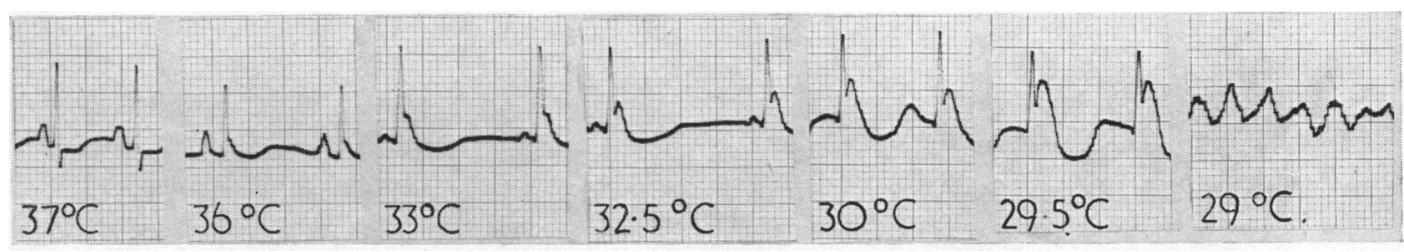

Fig. 7.-Patient with left atrial myxoma. The "injury potential" is first seen at $36^{\circ} \mathrm{C}$. and gradually becomes more marked until the onset of ventricular fibrillation 50 minutes later, during the final preparations for circulatory occlusion. Lead II.

Depression of the whole of the S-T segment with or without inversion of the $\mathrm{T}$ wave occurred frequently but the changes were inconsistent and bore no relation to the temperature level.

\section{DISCUSSION}

We do not propose to discuss the basic mechanisms of the abnormalities recorded further than we have done already. Electrolyte changes have been recorded in animal experiments but the evidence is conflicting and its applicability to man dubious. It seems established that acidosis plays a part in the production of some of the changes in the cardiogram during hypothermia but further than this it is not possible to say. Acetylcholine production is said to be depressed and, if so, this too may play a part. The problems are complex and we have no new evidence to offer.

We have studied the relation of the various features recorded above to the prognosis and, apart from the good prognostic significance of atrial fibrillation, already discussed, have been unable to demonstrate any correlation. Berne (1954) showed that myocardial function in hypothermia was only seriously impaired if the heart rate did not fall, but although his evidence is convincing, we could not establish any correlation between the degree of bradycardia and a good prognosis in our series. The two patients whose ventricular rates did not fall below 100 both did well and the means of the slowest rates recorded were the same for those patients who survived the procedure and those who did not. Similarly the degree of prolongation of the P-R, QRS, or S-T intervals bore no relation to prognosis. Bigelow et al. (1950) found in dogs that early inversion of the $\mathrm{T}$ wave indicated a poor prognosis but the changes were so inconstant in our cases that no correlation could be made.

The practical value of electrocardiograms in the management of individual patients undergoing hypothermia is not great, but until the metabolic and other changes occurring are better understood, it is clearly valuable to continue to record them for correlation with the clinical condition and prognosis. Findings such as the favourable significance of atrial fibrillation, obtained by this means, are interesting and may prove of some importance.

\section{SUMMARY}

A series of electrocardiograms of patients undergoing hypothermia for cardiac surgery at Guy's Hospital has been analysed. The consistent features were a progressive bradycardia associated with evidence of delayed conduction and repolarization as manifested by prolongation of the P-R, QRS, and S-T intervals. Atrial fibrillation occurred frequently and seemed to indicate a favourable outcome. Ventricular fibrillation also was recorded frequently. The "injury potential " 
at the QRS-ST junction was recorded in several patients and its association with ventricular fibrillation confirmed.

The mechanisms of these changes are briefly discussed.

We wish to thank Sir Russell Brock for permission to publish these cases and for his co-operation in enabling us to make the recordings.

\section{REFERENCES}

Alexander, L. (1949). New Engl. J. Med., 241, 39.

Berne, R. M. (1954). Circulation Res., 2, 90.

Bigelow, W. G., Lindsay, W. K., and Greenwood, W. F. (1950). Ann. Surg., 132, 849.

Brock, R. C., and Ross, D. N. (1955). Guy's Hosp. Rep., 104, 99.

Burton, A. C., and Edholm, O. G. (1955). Man in a Cold Environment. Arnold, London.

Campbell, M., and Reynolds, G. (1954). Brit. Heart J., 16, 57.

Capretti, G., Bezzi, E., and Luccion, R. (1953). G. Clin. Med., 34, 1029.

Covino, B. G., and Charleson, D. A. (1955). Amer. J. Physiol., 181, 357.

_- and Hegnauer, A. H. (1955). Amer. J. Physiol., 181, 553.

Crismon, J. M. (1944). Arch. intern. Med., 74, 235.

Delorme, E. J. (1955). Brit. med. Bull., 11, 221.

Fleming, P. R. (1956). Brit. Heart J., 18, 288.

Graybiel, A., and Dawe, C. J. (1950). U. S. Forces med. J., 1, 418.

Hicks, C. E., McCord, M. C., and Blount, S. G. (1956). Circulation, 13, 21.

Kossmann, C. E. (1940). Bull. N. Y. Acad. Med., 16, 317.

Laufman, H. (1951). J. Amer. med. Ass., 147, 1201.

Muir, F. H. (1955). J. Soc. Cardiol. Tech., 2, 167.

Osborn, J. J. (1953). Amer. J. Physiol., 175, 389.

Prec, O., Rosenman, R., Braun, K., Rodbard, S., and Katz, L. N. (1949). J. clin. Invest., $28,293$.

Rahman, S. A., Abhyankar, R. N., and Ali, T. (1954). Amer. Heart J., 47, 394.

Riberi, A., Shumacker, H. B., Kajikuri, H., Grice, P. F., and Boone, R. D. (1955). Surgery, 38, 847.

Ross, D. N. (1954). Guy's Hosp. Rep., 103, 97, 116.

Scurr, C. F. (1955). Proc. roy. Soc. Med., 48, 1077.

Siems, M. V., Horvath, S. M., Spurr, G. B., Hutt, B. K., and January, L. E. (1955). Amer. J. Physiol., 181, 325.

Taran, L. M., and Szilagyi, N. (1947). Amer. Heart J., 33, 14.

Tomaszewski, W. (1938). Arch. Mal. Caur, 31, 525.

Tysinger, D. S., Grace, J. T., and Gollan, F. (1955). Amer. Heart J., 50, 816.

Wayburn, E. (1947). Arch. intern. Med., 79, 77. 